Farkas,J.,Jármai,K.,Virág,Z.: Optimum design of a belt-conveyor bridge constructed as a welded ring-stiffened cylindrical shell, Welding in the World, Vol. 48. 2004, No. 1-2. pp. 3741. ISSN 0043-2288

\title{
Optimum design of a belt-conveyor bridge constructed as a welded ring-stiffened cylindrical shell
}

\author{
Farkas,J., Jármai,K., Virág,Z.
}

University of Miskolc, Hungary

\begin{abstract}
In the structural optimization of a ring-stiffened cylindrical shell the unknown variables are the shell thickness as well as the thickness and the number of flat rings. The shell diameter enables to realize a belt-conveyor structure inside of the shell. The uniformly distributed vertical load consists of dead and live load. The design constraints relate to the local shell buckling strength, to the panel ring buckling and to the deflection of the simply supported bridge. The cost function includes the material and fabrication costs. The fabrication cost function is formulated according to the fabrication sequence and includes also the cost of forming of shell elements into the cylindrical shape as well as the cost of cutting of the flat plate ring-stiffeners. Since the shell thickness does not depend on number of ring-stiffeners $(n)$, the $n_{\text {opt }}$ is calculated for a selected region of $n$.
\end{abstract}

\section{IIW-Thesaurus keywords:}

structural optimization, shell buckling, welded stiffened shells, welded structures, fabrication costs

IIS/IIW- (ex.doc. XV-1144-03) recommended for publication by IIW Commission XV "Design, analysis and fabrication of welded structures" 


\section{List of symbols}

$A_{r}$ cross-sectional area of a ring stiffener

$A_{T}$ thermal impulse due to welding

$A_{w}$ cross-sectional area of a weld

C coefficient Eq. 17

$c_{0}$ specific heat

E elastic modulus

$f_{y} \quad$ yield stress

$h_{r} \quad$ stiffener height

I arc current

$I_{r} \quad$ moment of inertia of a ring stiffener

$I_{x}$ moment of inertia of the shell cross-section

$K$ cost

$K_{M}$ material cost

$K_{F}$ fabrication cost

$k_{M}$ material cost factor

$k_{F}$ fabrication cost factor

$L \quad$ span length

$L_{e}$ shell effective width

$L_{r} \quad$ distance of rings

$M$ bending moment

$n \quad$ number of ring stiffeners

$p$ factored load intensity

$p_{0}$ unfactored load intensity

$Q_{T}$ specific heat input caused by welding

$R \quad$ shell radius

$R_{0}$ radius Figure 1

$T_{a}, T_{b}$ times Table 1

$t$ thickness

$t_{r} \quad$ ring stiffener thickness

$U$ arc voltage

$u_{\max }$ maximal radial deformation

$V$ volume

$v_{w}$ welding speed 
$w$ deflection

$y_{G}$ distance of the gravity centre

$Z$ factor Eq.17

$\alpha_{0}$ coefficient of thermal expansion

$\beta \quad$ reduction factor Eq.15

$\eta_{0} \quad$ coefficient of thermal efficiency

$\kappa \quad$ number of elements to be assembled

$\Theta$ difficulty factor

$\lambda \quad$ Eq.6

$\rho \quad$ material density

$\rho_{0}$ factor Eq.18

$\sigma \quad$ normal stress

$\sigma_{E}$ buckling stress

$\sigma_{c r}$ critical buckling stress

$\psi \quad$ coefficient Eq.18

$\omega \quad$ quotient Eq.21

\section{Introduction}

Stiffened shells are widely used in offshore structures, bridges, towers, etc. Rings and/or stringers can be used to strengthen the shape of cylindrical shells. Shells can be loaded by axial compression, bending, external or internal pressure or by combined load.

Design rules for the shell buckling strength have been worked out by ECCS [1], API [2] and DNV [3]. The optimum design of stiffened shells has been treated in some of our articles [4, 5, 6]. The optimum design of a stiffened shell belt-conveyor bridge has been treated in [7]. The buckling behaviour of stiffened cylindrical shells has been investigated by several authors, e.g. Harding [8], Dowling and Harding [9], Ellinas et al [10], Frieze et al [11], Shen et al [12], Tian et al [13]

In the calculation of shell buckling strength the initial imperfections should be taken into account. These imperfections are caused by fabrication and by shrinkage of circumferential welds. A calculation method for the effect of welding has been worked out by the first author [14] and it is used in the calculation of the local shell buckling strength.

In the present study the design rules of Det Norske Veritas (DNV) are used for ring-stiffened cylindrical shells. The shape of rings is a simple flat plate, which is welded to the shell by double 
fillet welds. In the calculation of the fabrication cost the cost of forming the shell elements into the cylindrical shape and the cutting of the flat ring-stiffeners is also taken into account.

The shell is a supporting bridge for a belt-conveyor, simply supported with a given span length of $L=60 \mathrm{~m}$ and radius of $R=1800 \mathrm{~mm}$ (Figures 1,2). The intensity of the factored uniformly distributed vertical load is $p=16.5 \mathrm{~N} / \mathrm{mm}+$ self mass. Factored live load is $12 \mathrm{~N} / \mathrm{mm}$, dead load (belts, rollers, service-walkway) is $4.5 \mathrm{~N} / \mathrm{mm}$. For self mass a safety factor of 1.35 is used, which is prescribed by Eurocode 3 (note that ECCS gives 1.3). The safety factor for variable load is 1.5. The flat plate rings are uniformly distributed along the shell. Note that the belt-conveyor supports are independent of the ring stiffeners, they can be realized by using local plate elements.

The unknown variables are as follows: shell thickness $t$, stiffener thickness $t_{r}$ and number of stiffeners $n$.

We do not consider the case of an unstiffened shell, since to assure a stable cylindrical shape, a certain number of ring-stiffeners should be used. In the present study we consider a range of ring numbers $n=6-30$. The range of thicknesses $t$ and $t_{r}$ is taken as $4-20 \mathrm{~mm}$, rounded to 1 $\mathrm{mm}$.

\section{The design constraints}

\subsection{Local buckling of the flat ring-stiffeners (Fig. 1.)}

According to DNV

$$
\frac{h_{r}}{t_{r}} \leq 0.4 \sqrt{\frac{E}{f_{y}}}
$$

Considering this constraint as active one, for $E=2.1 \times 10^{5} \mathrm{MPa}$ and yield stress $f_{y}=355 \mathrm{MPa}$ one obtains

$$
h_{r}=9 t_{r} .
$$

2.2 Constraint on local shell buckling (as unstiffened) (Fig. 3.)

$$
\begin{aligned}
& p=16.5+1.35 \rho\left(2 R \pi t+n A_{r}\right) ; \quad \rho=7.85 \times 10^{-6} \mathrm{~kg} / \mathrm{mm}^{3} ; \quad A_{r}=h_{r} t_{r} \\
& M_{\max }=\frac{p L^{2}}{8}
\end{aligned}
$$




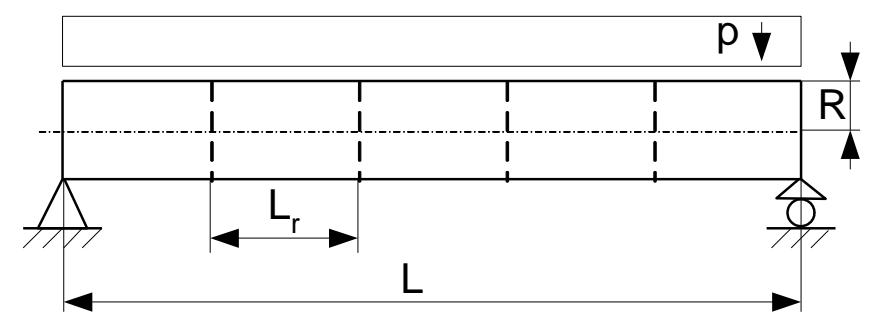

(a)

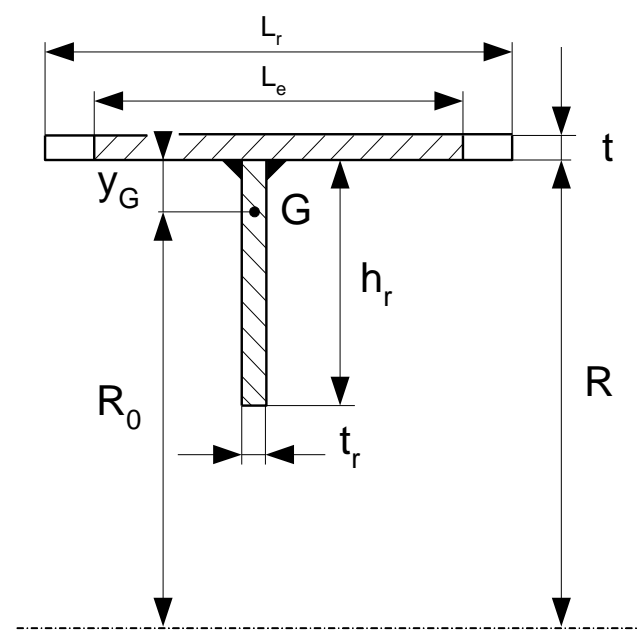

(b)

Figure 1. (a) A simply supported belt conveyor bridge constructed as a ring stiffened cylindrical shell, (b) the cross-section of a ring stiffener including the effective width of the shell

$$
\begin{aligned}
& \sigma_{\text {max }}=\frac{M_{\max }}{\pi R^{2} t} \leq \sigma_{c r}=\frac{f_{y}}{\sqrt{1+\lambda^{4}}} \\
& \lambda^{2}=\frac{f_{y}}{\sigma_{E}}, \sigma_{E}=(1.5-50 \beta) C \frac{\pi^{2} E}{10.92}\left(\frac{t}{L_{r}}\right)^{2} \\
& L_{r}=\frac{L}{n+1}
\end{aligned}
$$

The factor of (1.5-50 $\beta$ ) in Eq. (6) expresses the effect of initial radial shell deformation caused by the shrinkage of circumferential welds and can be calculated as follows [14].

The maximum radial deformation of the shell caused by the shrinkage of a circumferential weld is

$$
u_{\max }=0.64 A_{T} \sqrt{R / t}
$$

where $A_{T} t$ is the area of specific strains near the weld. According to our results [15]

$$
A_{T} t=\frac{0.3355 Q_{T} \alpha_{0}}{c_{0} \rho}
$$




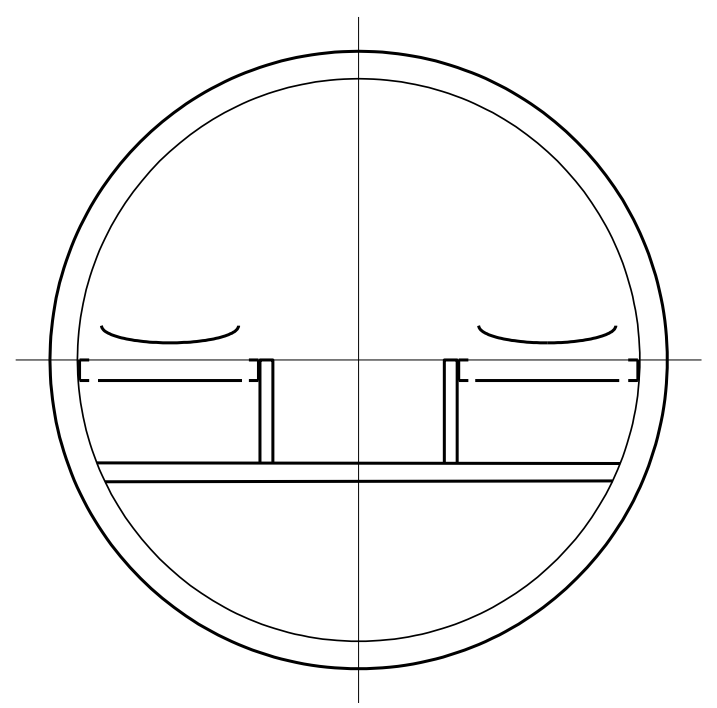

Figure 2. Cross-section of a belt conveyor bridge with two belt conveyors and a service walkway in the middle.

For steels it is

$$
\begin{aligned}
& A_{T} t=0.844 \times 10^{-3} Q_{T} \quad\left(A_{T} t \text { in } \mathrm{mm}^{2}, Q_{T} \text { in } \mathrm{J} / \mathrm{mm}\right) \\
& Q_{T}=\eta_{0} \frac{U I}{v_{W}}=C_{A} A_{W}
\end{aligned}
$$

For manually arc welded butt welds it is

$$
Q_{T}=60.7 A_{W}\left(A_{W} \text { in } \mathrm{mm}^{2}\right)
$$

When $t \leq 10 \mathrm{~mm}, \quad A_{W}=10 t$

When $t>10 \mathrm{~mm}, \quad A_{W} \cong 3.05 t^{1.45}$

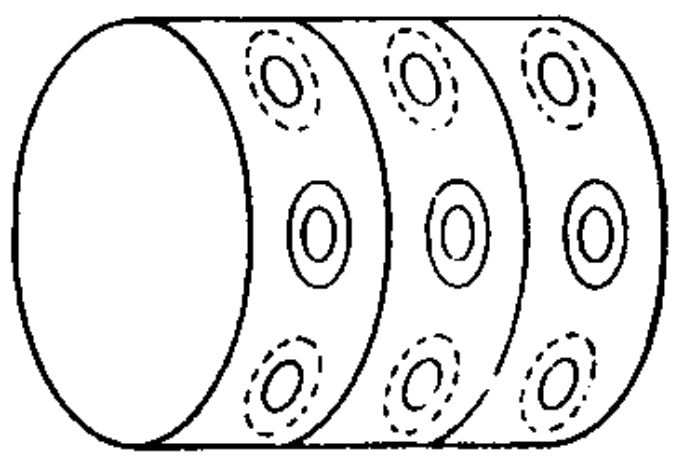

Figure 3. Top-view of the shell with local buckling

Introducing a reduction factor of $\beta$ for which 


$$
0.01 \leq \beta=\frac{u_{\max }}{4 \sqrt{R t}} \leq 0.02
$$

and the imperfection factor for shell buckling strength should be multiplied by $(1.5-50 \beta)$.

For $\beta \leq 0.01 \beta=0.01$, for $\beta \geq 0.02 \beta=0.02$.

Furthermore

$$
\begin{aligned}
& C=\psi \sqrt{1+\left(\frac{\rho_{0} \xi}{\psi}\right)^{2}}, Z=0.9539 \frac{L_{r}^{2}}{R t} \\
& \psi=1, \xi=0.702 Z, \rho_{0}=0.5\left(1+\frac{R}{300 t}\right)^{-0.5}
\end{aligned}
$$

It can be seen that $\sigma_{E}$ does not depend on $L_{r}$, since in Eq. (6) $L_{r}{ }^{2}$ is in nominator and in $C$ (Eq.17) it is in denominator. The fact that the buckling strength does not depend on the shell length is first derived by Timoshenko and Gere [16]. Note that API design rules [2] give another formulae. On the contrary, in the case of external pressure the distance between ring-stiffeners plays an important role $[4,6]$.

\subsection{Constraint on panel ring buckling (Fig. 4.)}

Requirements for a ring stiffener are as follows:

$$
\begin{aligned}
& A_{r}=h_{r} t_{r} \geq\left(\frac{2}{Z^{2}}+0.06\right) L_{r} t \\
& I_{r}=\frac{h_{r}^{3} t_{r}}{12} \cdot \frac{1+4 \omega}{1+\omega} \geq \frac{\sigma_{\max } t R_{0}^{4}}{500 E L_{r}} \\
& R_{0}=R-y_{G} ; y_{G}=\frac{h_{r}}{2(1+\omega)} ; \omega=\frac{L_{e} t}{h_{r} t_{r}} \\
& L_{e}=\min \left(L_{r}, L_{e 0}=1.5 \sqrt{R t}\right)
\end{aligned}
$$

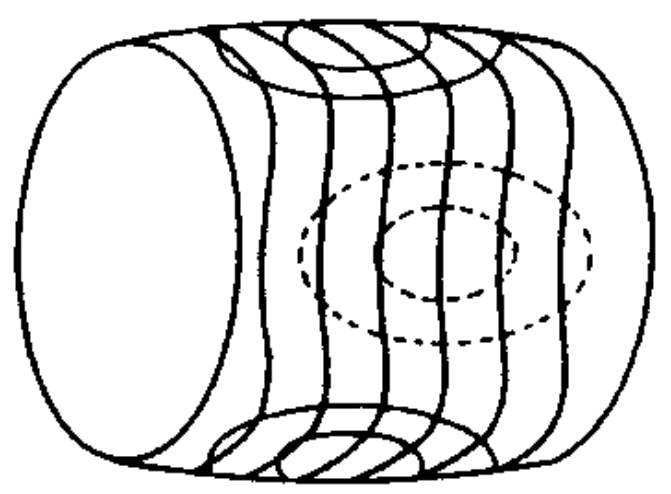

Figure 4. Top-view of panel ring buckling 


\subsection{Deflection constraint}

$$
\begin{aligned}
& w_{\max }=\frac{5 p_{0} L^{4}}{384 E I_{x}} \leq \frac{L}{500} \\
& I_{x}=\pi R^{3} t
\end{aligned}
$$

The unfactored load is

$$
p_{0}=12 / 1.5+4.5 / 1.35+\rho\left(2 R \pi t+n A_{r}\right)=11.33+\rho\left(2 R \pi t+n A_{r}\right) .
$$

\section{The cost function}

The cost function is formulated according to the fabrication sequence. A possible fabrication sequence is as follows:

(1) Fabricate 20 shell elements of length $3 \mathrm{~m}$ without rings (using 2 end ring stiffeners to assure the cylindrical shape). For one shell element 2 axial butt welds are needed (GMAW-C). The welding of end ring stiffeners is not calculated, since it does not influence the variables. The cost of the forming of the shell element to a cylindrical shape is also included $\left(K_{F 0}\right)$. According to the time data obtained from a Hungarian production company (Jászberényi Aprítógépgyár, Crushing Machine Factory, Jászberény) for plate elements of $3 \mathrm{~m}$ width (Table 1.), the times $\left(T_{a}+T_{b}\right)$ can be approximated by the following function of the plate thickness (Eq. 26).

Table 1. Time for forming the shell elements of $3 \mathrm{~m}$ width into circular shape $\left(T_{a}\right)$, as well as for reducing the initial imperfections due to forming $\left(T_{b}\right)$.

\begin{tabular}{cccc}
\hline$t(\mathrm{~mm})$ & $T_{a}(\min )$ & $T_{b}(\min )$ & $T_{a}+T_{b}(\min )$ \\
\hline 6 & 270 & 184 & 454 \\
\hline 8 & 336 & 204 & 540 \\
\hline 10 & 395 & 228 & 623 \\
\hline 15 & 495 & 304 & 799 \\
\hline 20 & 588 & 374 & 962 \\
\hline 25 & 680 & 442 & 1122 \\
\hline 30 & 744 & 538 & 1282 \\
\hline 40 & 834 & 692 & 1526 \\
\hline
\end{tabular}




$$
K_{F 0}=k_{F} \Theta\left(212.18+42.824 t-0.2483 t^{2}\right)
$$

The cost of welding of a shell element is

$$
K_{F 1}=k_{F}\left[\Theta \sqrt{\kappa \rho V_{1}}+1.3 \times 0.2245 \times 10^{-3} t^{2}(2 \times 3000)\right]
$$

where $\Theta$ is a difficulty factor expressing the complexity of the assembly and $\kappa$ is the number of elements to be assembled

$$
\kappa=2 ; V_{1}=2 R \pi t x 3000 ; \Theta=2
$$

The first term of Equation 27 expresses the time of assembly and the second calculates the time of welding and additional works [18].

(2) Welding the whole unstiffened shell from 20 elements with 19 circumferential butt welds

$$
K_{F 2}=k_{F}\left(\Theta \sqrt{20 \rho V_{1}}+1.3 \times 0.2245 \times 10^{-3} t^{2} \times 19 \times 2 R \pi\right)
$$

(3) Cutting of $n$ flat plate rings with acetylene gas [17]

$$
K_{F 3}=k_{F} \Theta_{c} C_{c} t_{r}^{0.25} L_{c}
$$

where $\Theta_{c}, C_{c}$ and $L_{c}$ are the difficulty factor for cutting, cutting parameter and length respectively, $\Theta_{c}=3, C_{c}=1.1388, L_{c} \approx 2 R \pi n+2\left(R-h_{r}\right) \pi n$.

(4) Welding $n$ rings into the shell with double-sided GMAW-C fillet welds. Number of fillet welds is $2 n$

$$
K_{F 4}=k_{F}\left(\Theta \sqrt{(n+1) \rho V_{2}}+1.3 \times 0.3394 \times 10^{-3} a_{W}^{2} x 4 R \pi n\right)
$$

$a_{W}=0.5 t_{r}$, but $a_{W \min }=3 \mathrm{~mm} . \quad V_{2}=20 V_{1}+2\left(R-\frac{h_{r}}{2}\right) \pi h_{r} t_{r} n$

$a_{W}$ is taken so that the double fillet weld joint be equivalent to the stiffener thickness.

The total material cost is $K_{M}=k_{M} \rho V_{2}$

The total cost is $K=K_{M}+20\left(K_{F 0}+K_{F 1}\right)+K_{F 2}+K_{F 3}+K_{F 4}$

$k_{M}=1 \$ / \mathrm{kg} ; \quad k_{F}=1 \$ / \mathrm{min}$

\section{Results of the optimum design}

The optimization has been worked out using the Hillclimb technique [18]. Results can be found in Table 2. Those results for which the place of stiffeners coincides with the circumferential welds of the shell segments are not applicable for fabrication reasons $(n=9,19)$. 
Table 2. Computational results: the number of stiffeners, thickness of the stiffeners, material and total costs in the case of optimum shell thickness $t=7 \mathrm{~mm}$. The optimum solution is marked by bold letters.

\begin{tabular}{|c|c|c|c|}
\hline$n$ & $t_{r}$ & $K_{M}$ & $K$ \\
\hline 6 & 21 & 39291 & 76041 \\
\hline 7 & 19 & 39211 & 75870 \\
\hline 8 & 18 & 39266 & 76296 \\
\hline 9 & 17 & 39278 & 76531 \\
\hline 10 & 16 & 39252 & 76595 \\
\hline 11 & 16 & 39448 & 77640 \\
\hline 12 & 15 & 39365 & 77446 \\
\hline 13 & 15 & 39538 & 78384 \\
\hline 14 & 14 & 39404 & 77965 \\
\hline 15 & 14 & 39555 & 78803 \\
\hline 16 & 13 & 39379 & 78191 \\
\hline 17 & 13 & 39509 & 78935 \\
\hline 18 & 13 & 39640 & 79679 \\
\hline 19 & 12 & 39409 & 78819 \\
\hline 20 & 12 & 39520 & 79476 \\
\hline 21 & 12 & 39632 & 80132 \\
\hline 22 & 12 & 39744 & 80787 \\
\hline 23 & 11 & 39451 & 79646 \\
\hline 24 & 11 & 39545 & 80222 \\
\hline 25 & 11 & 39639 & 80796 \\
\hline 26 & 11 & 39733 & 81370 \\
\hline 27 & 11 & 39827 & 81943 \\
\hline 28 & 10 & 39470 & 80505 \\
\hline 29 & 10 & 39547 & 81005 \\
\hline 30 & 10 & 39625 & 81505 \\
\hline
\end{tabular}

Table 3. Cost distribution for the optimum solution

\begin{tabular}{|c|c|c|c|c|c|c|c|c|}
\hline$n$ & $t_{r}$ & $20 K_{F 0}$ & $20 K_{F 1}$ & $K_{F 2}$ & $K_{F 3}$ & $K_{F 4}$ & $K_{M}$ & $K$ \\
\hline 7 & 19 & 19991 & 4707 & 3459 & 1076 & 7425 & 39211 & 75870 \\
\hline
\end{tabular}

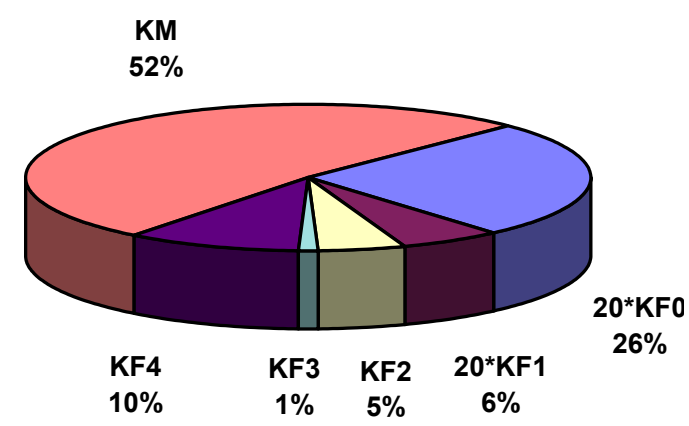

Figure 5. Cost distribution for the optimum solution $\left(t=7, t_{r}=19, n=7\right)$.

Table 3 shows the value of the different cost elements and Fig. 5 gives the percentage of them. 


\section{Conclusions}

The shell thickness is determined by the constraints on local shell buckling as well as on deflection. Since the number of ring-stiffeners does not influence these constraints, in order to assure a stable circular shell shape, a certain number of rings should be used. Since the design rules do not give any prescriptions for the minimum number of ring-stiffeners, for the investigated case we have selected a ring number domain of $n=6-30$ and have performed the optimization in this domain.

The Det Norske Veritas design rules give suitable formulae for the design of rings, the dimensions of which decrease with the increase of the number of rings.

The initial radial deformation of the shell caused by the shrinkage of circumferential welds affects the local shell buckling strength significantly. Cost calculation methods are proposed for the forming of shell elements into circular shape and for the cutting of flat plate ring-stiffeners. The cost function is formulated according to the fabrication sequence.

The optimization results (Table 2) show that, due to the cutting and welding costs of stiffeners, the smaller number of stiffeners is more economic. The optimum ring number is 7 , which minimizes the total mass (material cost) and the total cost. Material cost is about half of the total one and is insensitive to the variation of ring numbers. The forming cost of the shell elements $\left(K_{F 0}\right)$ is significant. The difference between the best and worst optima indicated in Table 2 is $7 \%$, thus it is worth to use an optimization process in the design stage. The result is greatly dependent on local situation, parameters, but this numerical evaluation and comparison show the benefit of optimum design.

\section{Acknowledgements}

The research work was supported by the Hungarian Scientific Research Foundation grants OTKA T38058 and T37941.

\section{References}

1. European Convention of Constructional Steelwork (ECCS) Recommendations for Steel Construction. Buckling of steel shells. No.56. Brussels, 1988.

2. American Petroleum Institute (API) Bulletin 2U. Bulletin on stability design of cylindrical shells. $2^{\text {nd }}$ ed. Washington, 2000.

3. Det Norske Veritas (DNV): Buckling strength analysis. Classification Notes No.30.1. Hovik, Norway, 1995.

4. Farkas,J., Jármai,K., Snyman,J.A., Gondos,Gy.: Minimum cost design of ring-stiffened welded steel cylindrical shells subject to external pressure. Proc. 3rd European Conf. Steel Structures, 
Coimbra, 2002, eds. Lamas,A. and Simoes da Silva, L. Universidade de Coimbra, 2002. 513522.

5. Farkas,J.: Minimum cost design of a ring-stiffened, axially compressed cylindrical shell with circumferential welds. Int. Coll. Stability and ductility of steel structures, Budapest, 2002. Ed. Iványi,M. Budapest, Akadémiai Kiadó, 2002. 523-530.

6. Jármai,K., Farkas,J., Virág,Z. Minimum cost design of ring-stiffened cylindrical shells subject to axial compression and external pressure. 5th World Congress of Structural and Multidisciplinary Optimization, Short papers. Italian Polytechnic Press, Milano, 2003. 63-64.

7. Liszkai,T., Farkas,J. Minimum cost design of ring and stringer stiffened cylindrical shells. Computer Assisted Mechanics and Engineering Sciences 6(1999) 425-437.

8. Harding,J.E.: Ring-stiffened cylinders under axial and external pressure loading. Proc. Instn. Civ. Engrs, Part 2, 71, 1981, Sept. 863-878.

9. Dowling,P.J., Harding,J.E.: Research in Great Britain on the stability of circular tubes. "Behaviour of Offshore Structures. Proc. $3^{\text {rd }}$ Int. Conference, Vol.2. 1982. Hemisphere Publ. Corp. McGraw Hill, New York.” 59-73.

10. Ellinas,,C.P., Supple,W.J., Walker,A.C.: Buckling of Offshore Structures. Granada, London etc. 1984.

11. Frieze,P.A., Cho,S., Faulkner,D.: Strength of ring-stiffened cylinders under combined loads. “Proc. 16 $6^{\text {th }}$ Annual Offshore Technology Conference, 1984. Vol. 2." Paper OTC 4714. 39-48.

12. Shen Hui-shen, Zhou Pin, Chen Tien-yun: Postbuckling analysis of stiffened cylindrical shells under combined external pressure and axial compression. Thin-Walled Struct. 15 (1993) 43-63.

13. Tian,J., Wang,C.M., Swaddiwudhipong,S.: Elastic buckling analysis of ring-stiffened cylindrical shells under general pressure loading via the Ritz method. Thin-Walled Struct. 35 (1999) 1-24.

14. Farkas,J.: Thickness design of axially compressed unstiffened cylindrical shells with circumferential welds. Welding in the World 46 (2002) No.11/12. 26-29.

15. Farkas,J., Jármai,K.: Analysis of some methods for reducing residual beam curvatures due to weld shrinkage. Welding in the World 41 (1998). No.4. 385-398.

16. Timoshenko,S.P., Gere,J.M.: Theory of elastic stability. 2nd ed. New York, Toronto, London, McGraw Hill, 1961.

17. Farkas,J., Jármai,K.: Economic design of metal structures. Millpress Science Publisher, Rotterdam, 2003, 340 p. ISBN 9077017992

18. Farkas,J., Jármai,K.: Analysis and optimum design of metal structures. Balkema, RotterdamBrookfield, 1997. 